\title{
SÍNTESE DOS ESTUDOS CLIMÁTICOS E A DISTRIBUIÇÃO DA REDE METEOROLÓGICA NO ESTADO DE GOIÁS E DISTRITO FEDERAL
}

\author{
Gustavo Zen Figueiredo Neves(a), Valdir Specian ${ }^{(\mathrm{b})}$, Thiago Rocha ${ }^{(\mathrm{c})}$, Francisco Arthur da Silva \\ Vecchia $^{(d)}$ \\ (a)Programa de Pós-Graduação em Ciências da Engenharia Ambiental/Universidade de São Paulo, Escola de \\ Engenharia de São Carlos - Professor colaborador Universidade Estadual de Goiás, gustavozen@ sc.usp.br \\ (b) Professor da Universidade Estadual de Goiás, valdir77@ hotmail.com \\ ${ }^{(c)}$ Mestrando Programa de Pós-Graduação em Geografia - Universidade Federal de Goiás/Jataí, \\ thiago1rocha@hotmail.com \\ (d) Professor Associado/Universidade de São Paulo, Escola de Engenharia de São Carlos, fvecchia@sc.usp.br
}

\section{Eixo: CLIMATOLOGIA EM DIFERENTES NÍVEIS ESCALARES: MUDANÇAS E VARIABILDIADES}

\begin{abstract}
Resumo
Os diversos estudos climáticos que têm sido realizados nas últimas décadas, principalmente aqueles relacionados às chuvas tem se concentrado apenas em algumas das regiões brasileiras, principalmente no Sul, Sudeste e Nordeste. O objetivo deste trabalho é de apresentar uma síntese dos estudos climáticos e meteorológicos no Estado de Goiás e o Distrito Federal por meio de uma revisão crítica da literatura. Destaca-se a importância na atualização do conhecimento climático do Estado de Goiás e Distrito Federal e as possibilidades que se ampliam para um futuro próximo.
\end{abstract}

Palavras chave: Chuvas. Monitoramento, Centro-Oeste.

\section{Introdução}

Os estudos climáticos revelam ainda hoje enormes lacunas no que se refere ao papel da dinâmica atmosférica na gênese e distribuição das chuvas na Região Centro-Oeste do Brasil. Sabe-se que a observação da distribuição das chuvas, durante um longo período, coloca em evidência as irregularidades do ritmo climático atual, pois permite constatar períodos muito chuvosos revezando-se com outros de severa estiagem. Tal distribuição deve ser analisada sob os aspectos quantitativo (diferentes volumes de precipitação) e qualitativo (padrões de distribuição pluviométrica e respectivos ritmos), sendo de suma importância para a explicação da natureza e cadência das atividades humanas Zavattini (1990, p. 12).

A chuva é um dos elementos climáticos mais importantes no que se refere à sobrevivência da sociedade humana, pois um dos fatores mais essenciais para manutenção da nossa sociedade, a produção de alimentos, está intimamente relacionado com distribuição espacial e temporal das chuvas. Além disso, as populações humanas podem experimentar situações variadas no que se refere à disponibilidade e distribuição das chuvas (secas e enchentes) que interferem e influenciam na organização espacial. 


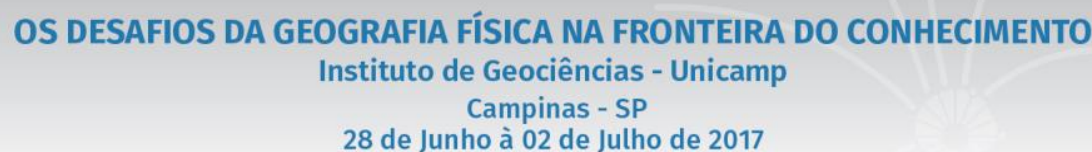

28 de Junho à 02 de Julho de 2017

As pesquisas climatológicas no Brasil têm como base a considerável contribuição de Monteiro (1962, 1964, 1969, 1971, 2000) à Climatologia Geográfica Brasileira. Entretanto, os diversos estudos climáticos que têm sido realizados nas últimas décadas, principalmente aqueles relacionados às chuvas tem se concentrado apenas em algumas das regiões brasileiras, principalmente no Sul, Sudeste e Nordeste (ZAVATINI, 1990).

O processo de ocupação do Centro-Oeste, acelerado a partir da década de 1960 com a construção de Brasília e a implantação de rodovias, o crescente interesse agrícola pelo "cerrado" desde os anos 1970, a divisão do estado de Goiás e Tocantins e a maior dinamização econômica da chamada "marcha para oeste" trouxeram uma agressão ao ambiente, tornando fundamental o conhecimento de seus fatores naturais e antrópicos. Frequentemente, ele também se ocupa dos fatos climáticos correlatos (enchentes, estiagens, chuvas torrenciais, geadas), com destaque para as chuvas e suas implicações nas atividades humanas.

O Distrito Federal e, principalmente, o Estado de Goiás destacam-se no cenário agropecuário nacional e internacional pela alta capacidade de produção agrícola. A região é líder na produção graneleira nacional, sendo responsável por $45 \%$ da produção nacional em 2012. Só a safra da soja resultou em mais de 35 milhões de toneladas, ou 53\% da produção total - segundo a Estatística da Produção Agrícola. Além disso, a região é líder no abate bovino, com quase $40 \%$ do abate total em peso (Cavalcanti, et al, 2014).

Sua localização geográfica é estratégica do ponto de vista geopolítico para integração interestadual, pois é limítrofe com os estados de Minas Gerais, Mato Grosso do Sul, Mato Grosso, Tocantins, Bahia e o próprio Distrito Federal. Somado a isso, é a região que oferta os acessos terrestres as regiões Norte e Centro-Oeste do Brasil. É considerada como o eixo de integração entre as demais regiões políticas e administrativas da Federação.

Assim, destacam-se a importância na atualização do conhecimento climático do Estado de Goiás e Distrito Federal e as possibilidades que se ampliam para um futuro próximo. Essas novas demandas e necessidades atreladas aos ramos econômicos, agropecuários, comércio, serviços e crescimento da população urbana e rural conduzem a uma maior aproximação desses setores com institutos de pesquisa e ensino. Estimular novos estudos para regiões tropicais brasileiras, alicerçada sobre o planalto central brasileiro que congrega o frágil bioma de cerrado e divisor de três grandes regiões hidrográficas da América do Sul: Rio Paraná, Rio São Francisco e Rios Araguaia e Tocantins. O objetivo deste trabalho é de apresentar uma síntese dos estudos climáticos e meteorológicos no Estado de Goiás e o Distrito Federal por meio de uma revisão crítica da literatura. 


\section{Características pluviométricas e o caráter dinâmico do clima}

Com relação à distribuição pluviométrica, de acordo com as Normais Climatológicas do período de 1961 a 1990 produzidas pelo Instituto Nacional de Meteorologia (INMET, 2015) o Estado de Goiás e Distrito Federal apresentam chuvas anuais médias em torno dos 1450 a $1650 \mathrm{~mm}$ na sua porção central. Já na região Noroeste os volumes pluviométricos médios de chuvas se concentram entre 1650 e $1850 \mathrm{~mm}$. Nas porções Nordeste e Leste, nas proximidades do Distrito Federal, os valores são mais baixos, podendo variar desde os 1050 até aos 1250 mm (Figura 1).

A posição geográfica da referida localidade de estudo sob o efeito continental, a geomorfologia e a imposição da circulação atmosférica regional, inferem uma diversidade significativa ao regime de chuvas em toda a região em destaque. Contudo, é importante destacar que esta metodologia apresentada foram utilizadas apenas doze estações automáticas ou postos pluviométricos, localizadas principalmente nas porções Leste, Sul e Central do Estado de Goiás e Distrito Federal (INMET, 2015).

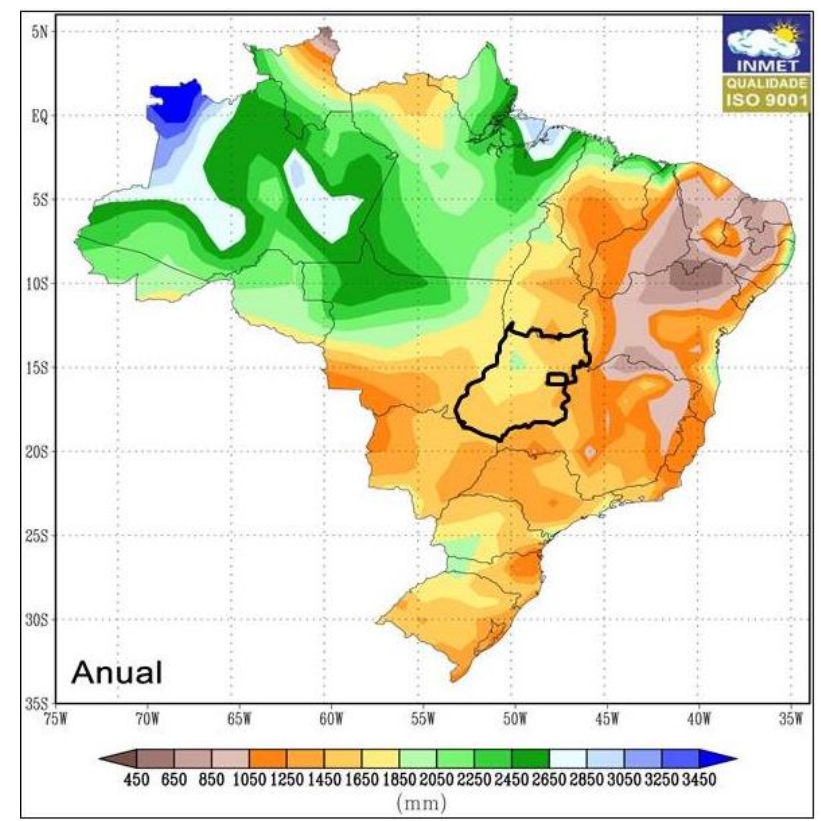

Figura 1: Distribuição das chuvas anuais médias no Brasil, com destaque para o Estado de Goiás e DF, no período 1961-1990, segundo as Normais Climatológicas do INMET geradas em 2015.

A Secretaria de Planejamento do Estado de Goiás (Segplan, 2014), elaborou o Atlas do Estado de Goiás que contém as médias pluviométricas para Goiás e Distrito Federal. Apesar do documento não ilustrar as metodologias adotadas com relação à quantidade de postos pluviométricos utilizados e ferramentas estatísticas, a Figura 2 ilustra que a área em destaque apresenta regiões bastante distintas quanto à distribuição de chuvas. 


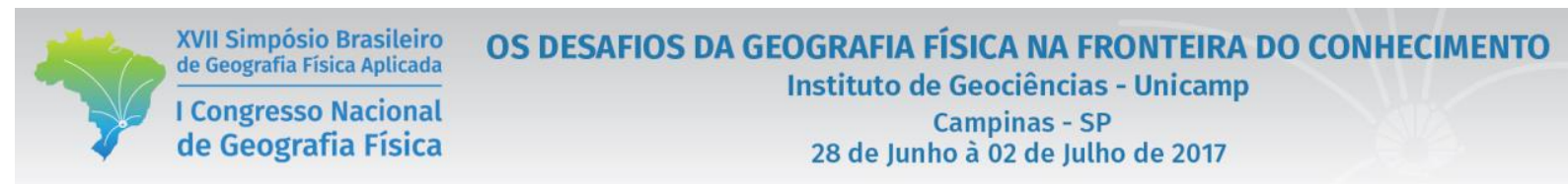

Nota-se que na região central, próximo a capital Goiânia, os valores pluviométricos variam de $1600 \mathrm{~mm}$ até 1800 , seguido pela região sudoeste, com volumes de chuva entre $1400 \mathrm{~mm}$ até $1200 \mathrm{~mm}$. Boa parte do Estado de Goiás como a porção Leste e Norte e todo o Distrito Federal, apresentam totais pluviométricos que variam entre $1200 \mathrm{~mm}$ e $800 \mathrm{~mm}$, sobretudo na região Nordeste.

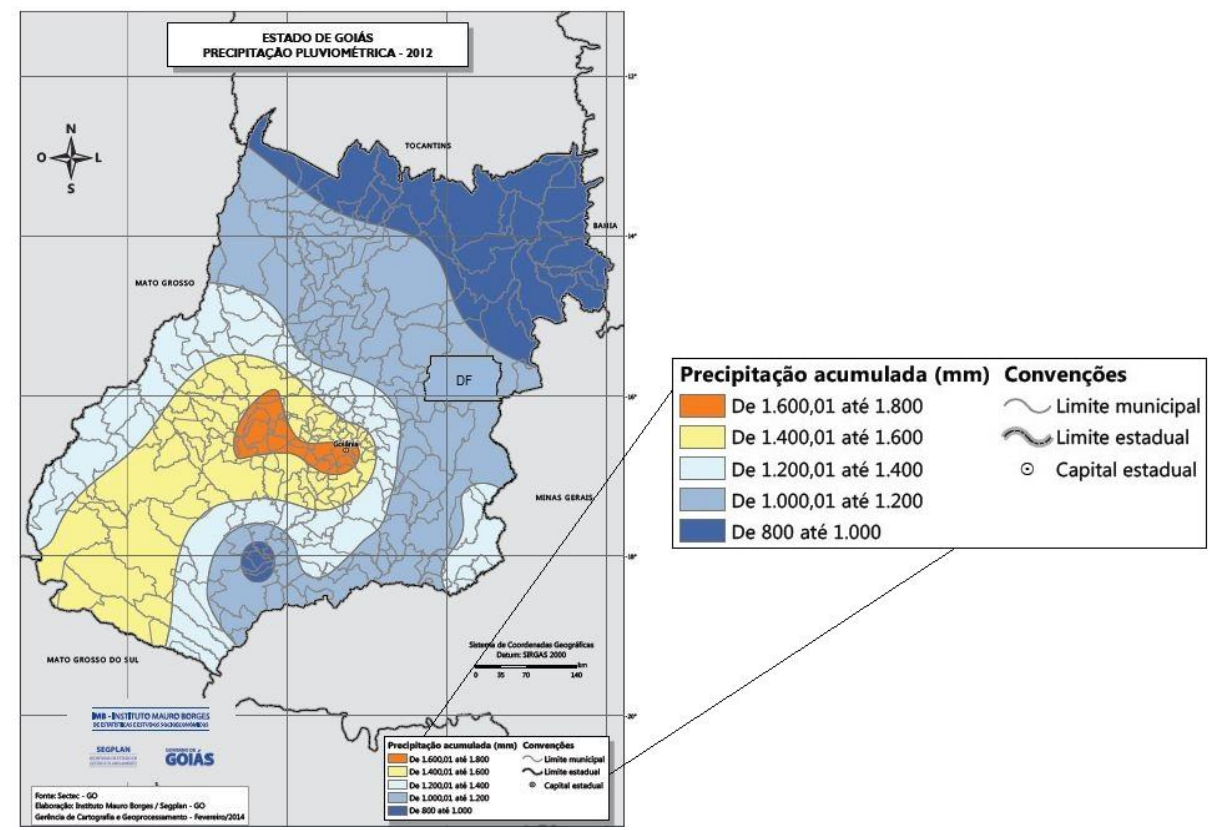

Figura 2: Precipitação média acumulada do Estado de Goiás e Distrito Federal. Fonte: SEGPLAN/GO, 2015. Modificado pelo autor (2015).

O Serviço Geológico do Brasil - Companhia de Pesquisa de Recursos Minerais (CPRM) publicou em 2010 o Atlas Pluviométrico do Brasil, com ilustrações quantitativas anuais da distribuição de chuvas em todo o território nacional, no período de 1977 a 2006. Ressalta-se que a quantidade pluviométrica para o Estado de Goiás e Distrito Federal é bastante distinta quando comparadas as ilustrações anteriores Intituto Nacional de Meteorologia (INMET) e Secretaria de Planejamento do Estado de Goiás (Segplan-GO), o que pode estar relacionada com a quantidade e distribuição espacial do postos pluviométricos e as ferramentas geoestatísticas utilizadas nas pesquisas anteriormente destacadas. A Figura 3 revela que a porção Norte do Estado do Goiás apresenta volumes anuais de chuva que superam $2200 \mathrm{~mm}$. A região Leste, próxima ao Distrito Federal também revela quantidades elevadas na ordem de $1600 \mathrm{~mm}$ até 1800 mm. E, a região Sul, situada na bacia hidrográfica do Rio Paraná, apresenta valores entre 1100 mm e 1400 mm. 

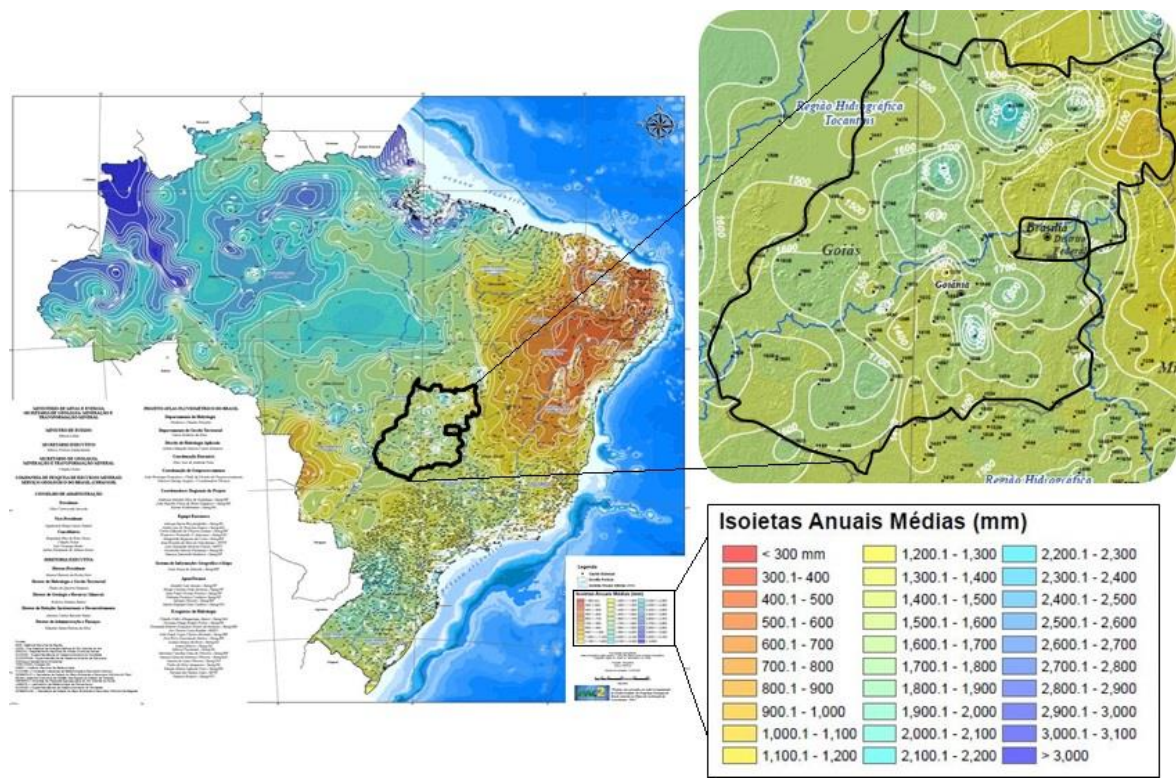

Figura 3: Projeto Atlas Pluviométrico do Brasil - 1977 a 2006. Fonte: CPRM (2010). Modificado pelo autor (2015)

No método dinâmico/genético, baseado no paradigma sorreano, a dinâmica climática é dada pela análise dos vários tipos de tempo. A variedade de tipos de tempo é identificada por meio da interpretação das cartas sinóticas do tempo diárias, associada à análise de dados meteorológicos. O método amparado no paradigma do ritmo apresenta algumas variações: o método sintético das massas de ar e dos tipos de tempo elaborado por Pédélaborde, a classificação genética de Strahler e a análise rítmica de Monteiro (ROSSATO, 2011, p. 37).

Strahler constitui outro autor de destaque, já que propôs o que chamou de sistema climático explicativo descritivo. Segundo ele, as classificações climáticas mais satisfatórias são aquelas denominadas genéticas, uma vez que privilegiam a origem dos fenômenos, em detrimento de qualquer outro critério de classificação.

O autor lembra que o principal problema das classificações é a transição de um tipo de clima para outro, que não acontece de forma brusca, como representado, mas sim gradual. Outra questão seria restringir os tipos climáticos às zonas continentais, o que, segundo este autor, é incompleto, uma vez que os oceanos também apresentam tipos climáticos (STRAHLER, 1984). 


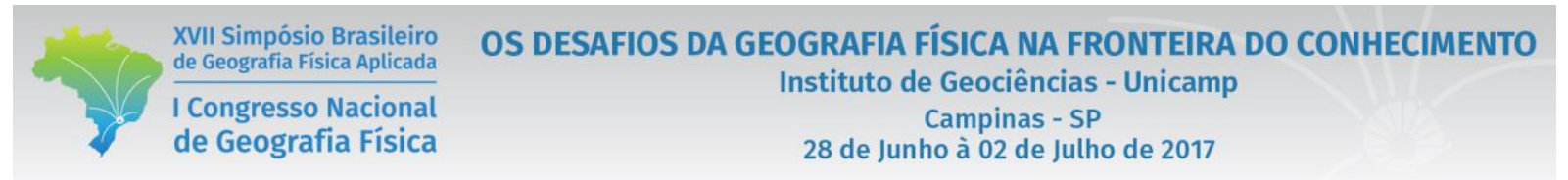

Na Figura 4 é possível visualizar ainda os trajetos principais que as massas de ar percorrem ao longo do território brasileiro, ambos descritos posteriormente por Monteiro (1962; 1963; 1964 e 2000), com base na classificação climática de Strahler, com o intuito de demonstrar as influências destes sistemas atmosféricos no clima do país.

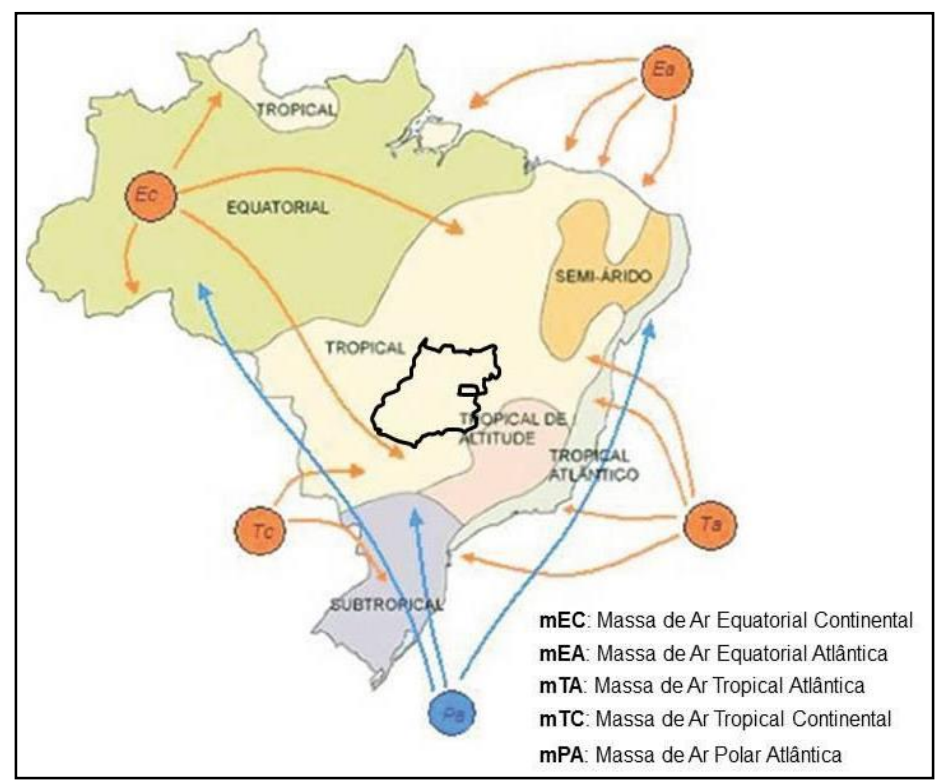

Figura 4: Classificação climática do Brasil e as influências das massas de ar. Fonte: Strahler (1951) e Monteiro (1963). Modificado pelo autor (2015).

No que se refere à circulação atmosférica, Edmon Nimer apresenta um mapa que ilustra a ação dos principais sistemas, que são denominados por ele de Sistemas de Circulação Perturbada. Apesar de verificadas nessas representações a falta de padrão de escala para os diferentes mapas, tal fato não comprometeu a verificação das principais características da circulação atmosférica no território Goiano e do Distrito Federal.

Nota-se que Edmon Nimer considera que o Estado de Goiás e Distrito Federal recebe atuação de pouca intensidade do que ele chamou de Sistema de Circulação Perturbada oriundas do deslocamento da Zona de Convergência Intertropical (ZCIT). Essa atuação é pouco intensa e se anula na Latitude entre a divisa dos Estados do Tocantins e Goiás. No que se refere à atuação dos sistemas originados na Amazônia, é apresentado o Sistema de Circulação Perturbada de W, que segundo o autor é caracterizado pela Massa Equatorial Continental e as chuvas geradas no seu interior por depressões denominadas linhas de instabilidade, atuante em toda a área de estudo. 


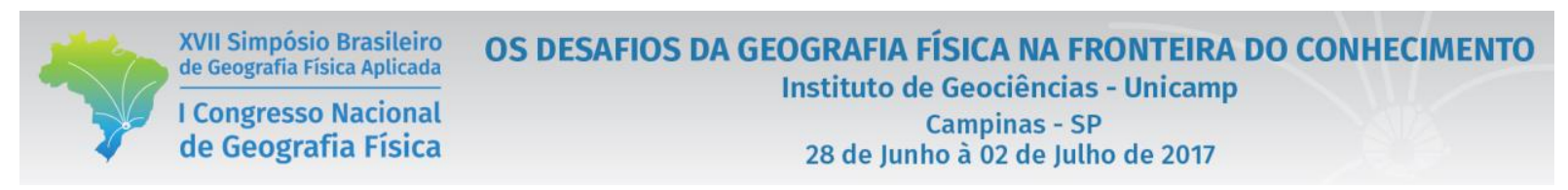

Aos sistemas de Sul, Nimer denomina de Sistema de Circulação Perturbada de S a Frente Polar Atlântica e considera a existência dos avanços Frontais em toda a bacia do Rio Paraná Oeste Goiano e em porções menores do território onde apresentam elevados gradientes altimétricos (Figura 5).

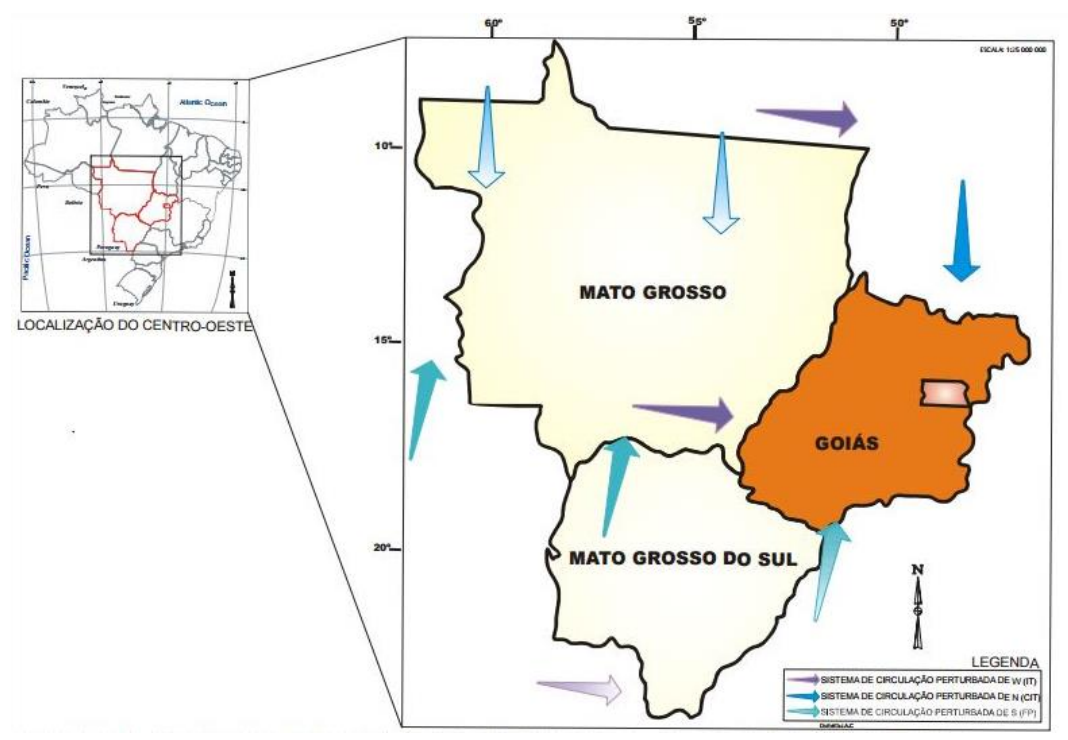

Figura 5: Circulação atmosférica da Região Centro-Oeste do Brasil. Fonte: Nimer (1979). Adaptado de Mariano (2005, p. 53).

Outros estudos foram realizados nas décadas seguintes com objetivos diversos de compreender a produção agrícola do sudoeste Goiano (Mariano, 2005); os sistemas sinópticos tropicais da América do Sul (Virgi, 1981; Cavalcanti, 1982; Quadro e Abreu, 1994); a variabilidade, tendências e séries estatísticas termopluviométricas para Goiás e Distrito Federal ou regiões hidrográficas do Paraná, Tocantins e Araguaia (Steinke, 2004; Mesquita et al, 2009; Alves e Vecchia, 2011; Costa et al, 2012; Penereiro et al, 2015; Nascimento et al, 2015).

Com isso, ilustramos alguns referenciais bibliográficos sobre a caracterização e distribuição regional das chuvas em diferentes escalas, seja ela nacional, ou propriamente a delimitação do Estado Goiano e Distrito Federal com adoção de diferentes metodologias e resultados para a mesma região em destaque. Por se tratarem de estudos preliminares, entendemos que os resultados careçam de detalhamento qualitativo quanto a série temporal e distribuição das estações meteorológicas, ou mesmo por não tornarem público os procedimentos e metodologias empregadas. 


\section{Rede de estações meteorológicas e pluviométricas na área de estudo}

Em relação ao Estado de Goiás, o assunto da falta de uma rede de coleta foi abordado por Monteiro (1951), quando o autor conseguiu identificar apenas 6 estações espalhadas pelo Estado.

De meados do século passado para os dias atuais o número de estações aumentou, mas a integração entre as mesmas continua precária. Para facilitar a compreensão da realidade climática de cada espaço, segundo suas configurações de latitude, relevo e outros, são propostas divisões ou níveis de atuação de um determinado sistema atmosférico, facilitando o entendimento do "fato" climático de cada área, seja urbana ou rural. Nessa perspectiva costuma-se elencar uma série de escalas de abordagem do estudo do clima. A escala que atende as necessidades de entendimento local/regional dos processos climáticos é a escala subregional, segundo a classificação de Monteiro (1976).

Entre os elementos do clima, a precipitação pluviométrica e a temperatura ajudam a compreender a realidade climática de uma determinada região. Segundo Conti (1975) o estudo da chuva é particularmente atraente, devido a dependência em que nos encontramos desse fenômeno. Precipitação e temperatura podem oferecer respostas há muitas indagações de uma grande maioria de profissionais de diferentes áreas que estudam o meio físico, conforme descritos nos trabalhos de Santos (1993); Salami (1996) e Boin (2000). As dificuldades que se apresentaram na aquisição e manutenção de equipamentos, a confiabilidade das leituras dos aparelhos e a possibilidade de que em alguns momentos não se poderia ser construídas série históricas, por simples falta de recursos humanos para a coleta.

A pesquisa bibliográfica resultou no entendimento das dificuldades de pesquisadores brasileiros tem para organizar informações climáticas, a rede não se completa e as séries históricas têm falhas, dessa forma partimos para entender o funcionamento da rede no estado de Goiás e DF, quais os órgãos que possuem estações, onde estão instaladas e qual área de cobertura.

O Estado de Goiás e o Distrito Federal, assim como grande parte das outras unidades da federação, tem sua base econômica na agricultura. Para que a produção agrícola consiga atingir melhores níveis de produtividade é fundamental a observação das condições climáticas. O conhecimento das variações de temperatura, umidade, precipitação, níveis de radiação são intrínsecas para a produção.

No levantamento, ainda não completado, em 1951 existiam seis estações em todo o estado (Monteiro, 1951), hoje a realidade mudou, vários órgãos de estado possui estações e/ou postos meteorológicos e cada qual segue a algum sistema e ou interesse por uma área especifica.

O Sistema de Meteorologia e Hidrologia do Estado de Goiás (SIMEHGO), conta com 23 PCD (Plataformas de Coletas de Dados - estações automáticas) instaladas e ativas, as informações coletadas são 


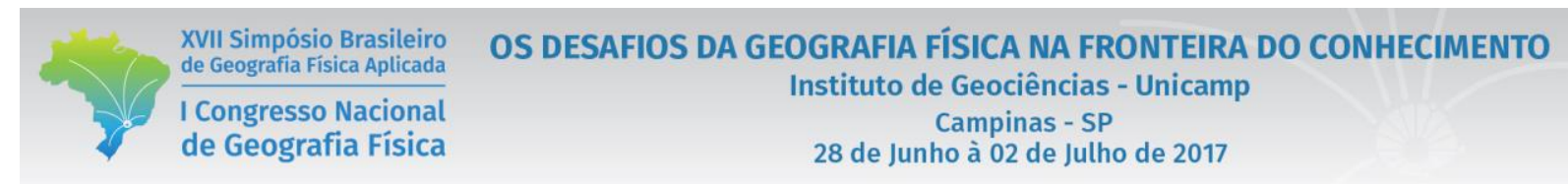

divulgadas e repassadas ao sistema (Centro de Previsão do Tempo e Estudos Climáticos - Instituto Nacional de Pesquisas Espacias) CPTEC/INPE. O Instituto Nacional de Meteorologia (INMET) possui 17 PCD instaladas, além de outras 15 estações convencionais. A EMBRAPA coleta dados em 32 estações e postos meteorológicos (particulares e públicos), além dos dados fornecidos pelas estações já citadas, dos sistemas SIMEGO e INMET. O INPE informa por meio do seu site a existência de 24 PCD, além daqueles já mencionados pelo sistema SIMEGO. Existem ainda estações de altitude (INMET) e estações de outros de órgão de estado em Brasília (geograficamente inserida em Goiás). No levantamento parcial contamos pelo menos 115 estações instaladas no estado (Figura 6).

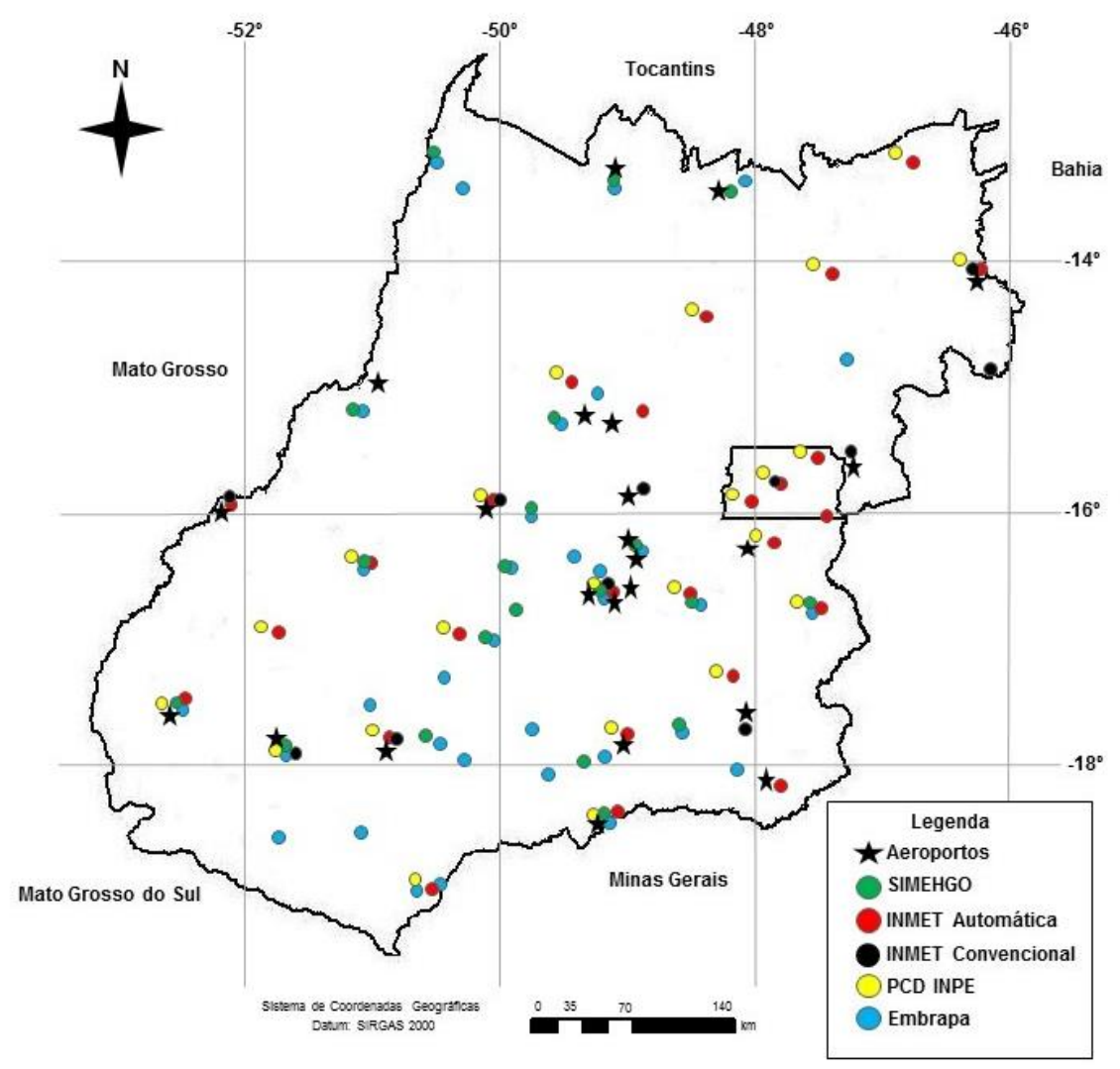

Figura 6: Distribuição das estações meteorológicas no Estado de Goiás e DF. Elaborado pelo autor (2015). Fonte: INMET, CPTEC-INPE, SIMEHGO, Embrapa (2013).

No que tange a distribuição de postos pluviométricos automáticos e convencionais, a rede de aparelhos é mais densa, porém não distribuida de maneira uniforme e planejada sobre o território em questão. No levantamento e quantificação dos postos pluviométricos, ao longo de várias décadas, observamos que a Agência Nacional de Águas (ANA) reúne aproximadamente 230 postos no Estado de Goiás e Distrito Federal (Figura 7). 


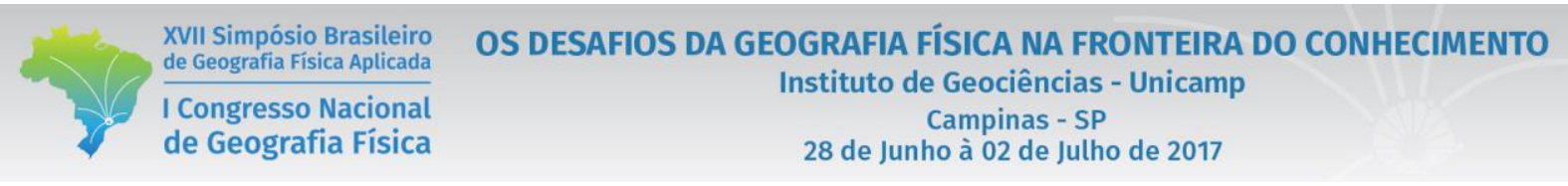

Nota-se uma evolução da quantidade de postos pluviométricos a partir da década de 1970 que se estende até a década de 2010 (ANA, 2013), sobretudo no eixo de expansão e aglomeração populacional no centrosul do Estado de Goiás e as cidades adjacentes da capital Federal. Todavia, a qualidade das informações encontradas são baixas, muitas vezes sem a disponilidade das séries históricas nos sistemas eletrônicos (SAR/HidroWeb), quando não são apresentam dados faltantes em seguidos semestres e anos.

Desta forma, o inventário ora apresentado pelas agências e organizações estaduais e federais revelam a desproporção espacial das estações automáticas, convencionais e dos postos pluviométricos alocados nos grandes centros urbanos e adjacências, sobretudo no Distrito Federal.

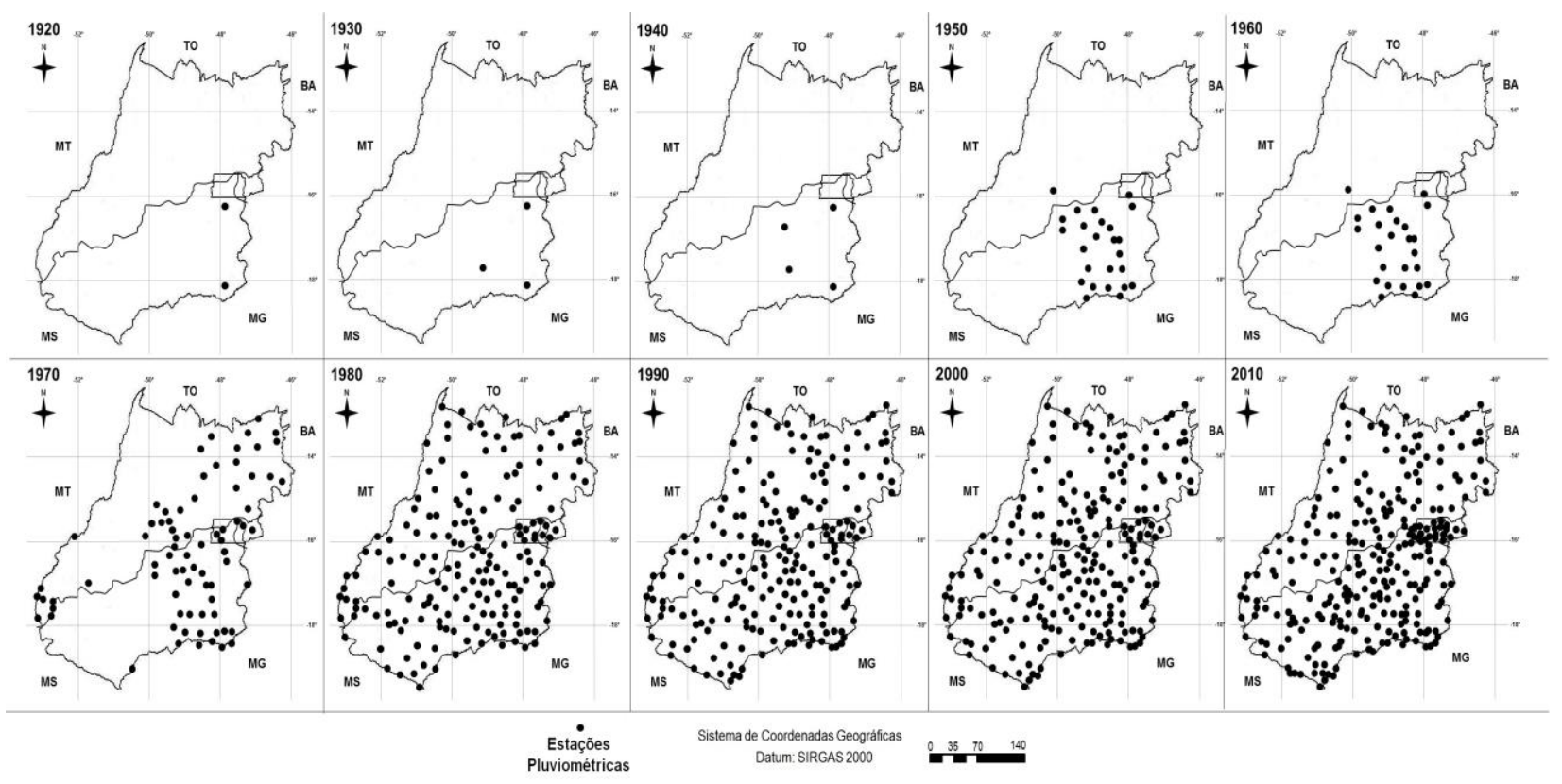

Figura 7: Distribuição das estações pluviométricas no Estado de Goiás e DF. Elaborado pelo autor (2015). Fonte: ANA (2013).

\section{Considerações Finais}

O sistema meteorológico do Estado de Goiás melhorou e aperfeiçoou sua rede de distribuição nos últimos 20 anos quando foram instaladas uma série de estações automáticas. A questão central está na organização e distribuição mais adequada das informações de um banco de dados unificado nas esferas Estaduais e Federais, que privilegie às séries históricas consistentes. A interlocução entre as esferas públicas e privadas é relevante para os desafios e possibilidades de uma região estratégica para o Brasil e América do Sul. 
Os postos pluviométricos e a rede meteorológica de superfície são de fundamental importância para a compreensão do tempo e do clima em escala local e regional, pois quanto mais qualificada for a rede de informações, a robustês dos equipamentos, sensores e sua plena disponibilidade de acesso público, mais efetiva será a justificativa da operacionalização desses dados com vistas ao planejamento presente e futuro.

\section{Referências Bibliográficas}

ALVES, E. D. L. VECCHIA, F. Análise de diferentes métodos de interpolação para a precipitação pluvial no Estado de Goiás. Acta Sciencitarium. Maringá, v.33, n.2, p.193-197, 2011.

ANA - Agência Nacional de Águas. Informações Hidrométricas. Texto disponível em: <http://www.ana.gov.br/mapainicial/pgMapaL.asp>. Acesso em: 10 jun. 2015.

ANA - Agência Nacional de Águas. Evolução da Rede Hidrometeorológica na Região Hidrográfica do Tocantins Araguaia, São Francisco e Paraná. Texto disponível em: 〈http://arquivos.ana.gov.br/infohidrologicas/rhtocantinsaraguaia.pdf〉. Acesso em: 10 jan. 2013.

BOIN, M. N. Chuvas e Erosões no Oeste Paulista: uma análise climatológica aplicada. Rio Claro. Tese (Doutorado). Geociências - Unesp. 2000.

CAVALCANTI, I. A. Um estudo sobre as interações entre os sistemas de circulação de escala sinótica e circulações locais. INPE 2494 TDL/097. 1982.

CAVALCANTI, I. M. et al (Org.). Um olhar territorial para o desenvolvimento: Centro-Oeste. Biblioteca Digital - Banco Nacional de Desenvolvimento Econômico e Social. Rio de Janeiro-RJ, 512p. 2014.

COSTA, H. C. et al. Espacialização e sazonalidade da precipitação pluviométrica do estado de Goiás e Distrito Federal. Revista Brasileira de Geografia Física. v.1, p.87-100, 2012.

CPTEC/INPE - Centro de Previsão de Tempo e Estudos Climáticos. 2015. Disponível em: <http://sinda.crn2.inpe.br/PCD>. Acesso em: jun 2015.

CONTI, J. B. (1975). A circulação Secundária e o Efeito Orográfico na Gênese das Chuvas: o exemplo do ENE Paulista: USP/Inst. de Geografia, série teses e monografias, $\mathrm{n}^{\circ}$ 18, $82 \mathrm{p}$.

INMET - Banco de Dados Meteorológicos para Ensino e Pesquisa. 2015. Disponível em: <http://www.inmet.gov.br/portal/index.php?r=bdmep/bdmep>. Aceso em: jun-dez 2015.

MESQUITA, W. O. el al. Precipitações máximas diárias esperadas para as regiões central e sudoeste de Goiás. Pesquisa Agropecuária Tropical. v.39, n.2, p.73-81, 2009.

MONTEIRO, C. A. F. (1951). Notas para o estudo do clima do Centro Oeste Brasileiro. In: Rev. Brasileira de Geografia, n. 01. Rio de Janeiro, janeiro março.

(1962). Da necessidade de um caráter genético à classificação climática (algumas considerações metodológicas a propósito do estudo do Brasil Meridional). Revista Geográfica, Rio de Janeiro, v. 31, n. 57, p. 29-44.

(1963). Sobre a análise geográfica de sequências de cartas de tempo: pequeno ensaio metodológico sobre o estudo do clima no escopo da Geografia. Revista Geográfica, Rio de Janeiro, v. 31, n. 58, p. 169-179. 
Sobre Um Índice de Participação das Massas de Ar e suas Possibilidades de Aplicação

à Classificação Climática. Revista Geográfica 61, Instituto Panamericano de Geografia e História, Rio de Janeiro, 1964.

Análise Rítmica em Climatologia - problemas da atualidade climática em São Paulo e achegas para um programa de trabalho. Climatologia 1, USP/IG, São Paulo, 1971.

C. A. F. A Dinâmica Climática e as Chuvas no Estado de São Paulo. Rio Claro: UNESP, Ageteo, 2000. 1 CD-ROM.

NASCIMENTO, D. T. F.; NETO, J. M. S.; NUNES, L. C. Definição dos anos-padrão para o estudo da pluviometria do Estado de Goiás e do Distrito Federal. Brazilian Geographical Journal: Geosciences and Humanities research medium, Ituiutaba, v. 6, n. 1, p. 272-290, jan./jun. 2015.

NIMER, E. Climatologia do Brasil. Rio de Janeiro: IBGE, 1989. 421p.

PENEREIRO, J. C. et al. Identificação de tendências sazonais dos regimes climático e hidrológico na bacia hidrográfica dos rios Tocantins e Araguaia, Brasil. Revista Geografia Acadêmica. v.9, n.1, 2015.

QUADRO, M.F.L.; Abreu, M.L.Estudos de episódios de Zonas de Convergência do

Atlântico Sul sobre a América do Sul. Anais II.Congresso Brasileiro de Meteorologia, 8:620-623.

Belo Horizonte-MG. 1994.

ROSSATO, M. S. Os Climas do Rio Grande do Sul: variabilidade, tendências e tipologia. 2011. Tese (Doutorado em Geografia). Universidade Federal do Rio Grande do Sul. Instituto de Geociências. Porto Alegre, RS 2011.

SANTOS, M. J. Z. Tendências das Chuvas no Nordeste Paulista e Problemas Ligadas com as Pesquisas em Climatologia Agrícola. In Boletim de Geografia Teorética. Rio Claro, vol. 23, no 45 - 46 (volume especial) pp. $39-48,1993$.

SALAMI, L. N. B. PERES. (1996). Estudo das Influências Climáticas e Antropogênicas nas Características físico-químicas no Rio Monjolinho. São Carlos. Dissertação (Mestrado). EESC/USP, $135 \mathrm{p}$.

SORRE, M. Les Fondements de la Géografhie Humaine. Tome: I- Les fondements biologiques. Essai d'une écologie de l'homme. Livre I- Le climat et l'home. Chp ler Le Climat. Paris, Librairie Armand Colin, 1951. p.13 - 43 .

STRAHLER, A. H. Phisical geographY. New York: John Wiley \& Sons. 1951.

Geografía Física. Barcelona: Ediciones Omega S. A., 1984. 767p.

STEINKE, E. T. Considerações sobre variabilidade e mudança climática no Distrito Federal, suas repercussões nos recursos hídricos e informação ao grande público. Tese (Doutorado em Ecologia), publicação ECO.TD, Departamento de Ecologia, Universidade de Brasília, Brasília-DF, 196p. 2004.

VIRGI, H., A preliminary study of summertime tropospheric circulation patterns overSouth Americ a estimated from cloud wins. Mon. Weather Rev., 109, 549-610. 1981.

ZAVAtTini, J. A. A Dinâmica Atmosférica e a Distribuição das Chuvas no Mato Grosso do Sul. 1990. (Doutorado em Geografia), Faculdade de Filosofia, Letras e Ciências Humanas, Universidade de São Paulo, São Paulo, 1990. 